6-7-2002

\title{
New media and the circuit of cyber-culture: Conceptualizing Napster
}

Bryan C. Taylor

University of Colorado, bryan.taylor@colorado.edu

Christof Demont-Heinrich

University of Denver

Kirsten Broadfoot

University of Colorado

Jefferson Dodge

University of Colorado

Eelbwethifand additional works at: https://engagedscholarship.csuohio.edu/clcom_facpub

keland State University g.jian@csyohio.edu mmons, and the Communication Technology and New

Media Commons

How does access to this work benefit you? Let us know!

\section{Publisher's Statement}

This is an Author's Accepted Manuscript of an article published in the Journal of Broadcasting \& Electronic Media 06-07-2002, available online: http://www.tandfonline.com/10.1207/ s15506878jobem4604_7

\section{Recommended Citation}

Taylor, B. C., Demont-Heinrich, C., Broadfoot, K. J., Dodge, J., \& Jian, G. (2002). New media and circuit of cyber-culture: Conceptualizing Napster. Journal of Broadcasting \& Electronic Media, 46(4), 607-629. doi: 10.1207/s15506878jobem4604_7

This Article is brought to you for free and open access by the School of Communication at EngagedScholarship@CSU. It has been accepted for inclusion in Communication Faculty Publications by an authorized administrator of EngagedScholarship@CSU. For more information, please contact library.es@csuohio.edu. 


\title{
New Media and the Circuit of Cyber-Culture: Conceptualizing Napster
}

\author{
Bryan C. Taylor, Christof Demont-Heinrich, \\ Kirsten J. Broadfoot, Jefferson Dodge, and Guowei Jian
}

Media studies scholars have employed the "cultural circuit" model to analyze media in the context of capitalist political economy. This model identifies interrelated "moments" in which the meanings of cultural products are determined, negotiated, and subverted in interaction between producers and audiences. The turbulent evolution of new media, however, requires continuous reflection on the adequacy of conceptual tools. Analysis of recent controversy surrounding the Internet music-exchange service Napster indicates that the cultural circuit model must be modified to accommodate the emerging media of cyber-culture.

\section{Introduction: Napster and the Circuit of Culture}

In a recent article, Jones (2000) calls for a more engaged response by media scholars to changes in popular music created by the Internet. These scholars, he argues, should "approach the Internet as simultaneously a social space, medium of distribution, and engine of social and commercial change: as a space of interrelated practices rather than a text to be critiqued, or a technology in need of assessment and control" (p. 222). Implicitly, this call reflects a new epistemology for media studies,

Eryen C. Taylor is an Associate Professor in the Department of Communication at the University of Colorado, Boulder. His research interests include cultural studies of new media.

Chivtof Dencut-fleinfich (M.A., Colorado State Univensity) is a doctoral candidate in Media Studies at the University of Colorado, Boulder. His reseanch interests include the political economy and regulation of new media.

Kinsten J. Brandioof (M.A., Arizona State Univensity) is a doctoral candidate in Communication at the University of Colorado, Boulder. Her reseanch interests include the discourse of genetic technologies, and relationships between identity, onganization, and culhure.

Iefierson Dodoe (M.A., University of Colorado) is assistant editor of the University of Colorado's faculby/staff newspaper, Stiver \& Gold Recond. His neseanch interests include the emenging ethical and legal issues nelated to online journalism and other new media.

Guowei finn (M.A., University of Cincinnati) is a doctoral candidate in Communication at the University of Colorado, Boulder. His research interest is in the relationship between information and communication technology (ICT) and onganizational knowledgepower.

The authors acknowledge Michel Hendry for her role in developing early versions of the "Regulation" section of this anticle. 
one emphasizing dynamic interaction between media forms and logics (Bolter \& Grusin, 2000).

One traditional model for this type of analysis has been the "cultural circuit" (Barker, 2000, pp. 53-54; 365-66). This model focuses on how the value and meaning of cultural phenomena are created, maintained, and transformed throughout various sites, moments, and practices. The model dates to Marx's $19^{\text {th }}$ century analysis of the "circuit of capital," which linked the moments of industrialized production and commodity-circulation (Dyer-Witherford, 1999, p. 91).

In his famous essay "Encoding/Decoding," Stuart Hall (1981) recovered this analysis-via Althusser and Gramsci-to challenge the conventions of administrative media research and brute Marxism (Lewis, 1994). He developed a four-stage heuristic involving moments of Production, Circulation, Use, and Reproduction. In this model, these moments were both relatively autonomous and variously "articulated." Each stage in an artifact's circuit exerted constraints on its associated meanings and practices, but was also subject to constraints exerted by other stages. Because no moment could exert complete, direct, or permanent constraint on any other, the relations of domination inscribed in an artifact were potentially contradictory. As a result, their meaning was subject to negotiation and opposition by its users.

In another well-known essay, Johnson (1986/1987) revised this model to argue that, as a field, cultural studies was uniquely concerned with the "life" of texts-their accumulated moments of commodification and interpretation. In his "circuit of production and consumption," Johnson modeled a circular progression between the moments of Production, Texts, Readings, and Lived Cultures. This holism, Johnson argued, subverted "economistic" and "productivist" analyses that neglected lived experience in favor of social structure, and inferred textual meanings and practices from modes of production.

Johnson also argued that his model preserved the impact of material conditions on textual production. While he attributed neglect of this impact to "formalist" approaches, it was also attributed in years following by political-economic scholars to "populist" cultural studies that celebrated audience resistance to cultural hegemony through the exploitation of semiotic "plasticity" (Clarke, 1991, p. 83). While usefully emphasizing the creative agency of consumers, these studies were allegedly naïve in failing to account for structural influences (e.g., concentration of ownership) on the contexts and outcomes of cultural practice (Ferguson \& Golding, 1997).

Partly due to this critique, and to lingering problems (e.g., of empirical application; Lewis, 1994) associated with the model, du Gay, Hall, Janes, Mackay, and Negus (1997) collaborated in a significant revision. In this iteration, the cultural circuit included totally interconnected spheres of Representation, Identity, Production, Consumption, and Regulation. Analysis focused on how their disparate elements were temporarily "articulated" (i.e., arbitrarily joined) to create functional phenomena. The authors applied this model in a case study of the Sony Walkman, arguing that-far from being a discrete, stable, or objective technology-it was a site of 
intensive interaction where forms and practices associated with particular spheres folded into each other. "The Sony Walkman," as a result, was reframed as a contingent punctuation of complex activity occurring within and between these spheres.

The model has been further adapted and applied in recent studies. Dyer-Witherford (1999) used it to argue that information-age technology forms the latest site of struggle between capital and labor. He proposed the four moments of Production, Reproduction of Labor Power, Reproduction of Nature, and Circulation, and argued that even as capital uses high technology to widen its control over social spheres, it inevitably over-reaches, creating instabilities that are exploited by subordinate groups to advance their interests. Significantly, Dyer-Witherford argued that the Internet is a principal site of this struggle because its "ambivalent" architecture (Feenberg, 1991) accommodates both official control and commercialization, and also the development of democratic and oppositional communities (Dyer-Witherford, 1999, pp. 121-128). Soar (2000) used the model to reconceptualize the dynamics of production and consumption occurring between groups of "cultural intermediaries" within the moment of production in advertising. And finally, Julier (2000, pp. 61-62) used it to analyze new paradigms of user-centered design in which market research is intensively re-circulated into production, and associated identities of designer and consumer are collapsed.

As this brief history indicates, the cultural circuit model has been repeatedly modified in response to evolving techno-cultural conditions and theoretical disputes. This revision is in keeping with Hall's (fitting) invitation to negotiate its elements: "If you're going to work with the model, you have to change ... . and develop it" (Lewis, 1994, p. 272). We take this history and invitation as a warrant for our own argument: that the rapidly evolving conditions of new media in "cyber-culture" indicate the need for still further revision. Specifically, our analysis of controversy surrounding the "Napster" file exchange system indicates that the Internet's development has affected the nature of-and relationships between-the model's elements.

We contend that while the du Gay et al. study is rich and informative, recent developments have rendered historical its focus on postwar industry and media culture. We refer to the transition currently underway between "electronic" (Chesebro \& Bertelsen, 1996, pp. 134-160) and "cyber-" cultures (Bell \& Kennedy, 2000; Caldwell, 2000). That is, we are concerned with the status of the cultural circuit in several, overlapping contexts, including: interactive, multi-media, and hyper-textual formats of communication; accelerating rates of techno-cultural change; increased pervasiveness, transparency, multi-functionality, and autonomy of computers; increased convergence of media systems and program genres; popular anxiety and optimism regarding the consequences of new media; and increasing fusion of organic and technological materials to create "cyborg" bodies and identities.

While some of these conditions are treated in Du Gay et al. (1997), others that are increasingly valued in media studies are not. Even those that are treated (e.g., globalization) have undergone significant changes in the interim. Additionally, we 
note that while Dyer-Witherford analyzes the Internet, he does not replicate the du Gay et al. study's focus on a single artifact. For these reasons, we have chosen to compare and contrast moments depicted in the Walkman study with those corresponding to Napster. This consistency allows us to clarify similarities and differences between the cases that yield implications for the model.

As Jones (2000) notes above, the convergence of popular music and the Internet provides a rich opportunity for this study. Most of the existing scholarship on this topic, however, has appeared prior to the mid-1999 emergence of Napster. Nonetheless, it anticipates many of the themes we will explore. In one survey of Internet music, Hayward (1995) identified promotional websites that did and did not exploit features of new media (e.g., streaming audio and video), and also sites for mail order of CD's. Hayward also profiled artists who embraced the Internet's potential to independently produce and distribute their music. He noted that, once it resolved potential problems associated with copyright infringement, the industry was likely to capitalize on the Internet to achieve a "more efficient, aggressive, and truly multinational operation" (p. 33). Bettig (1997) cited Internet music as an example of the growing commercialization of media content, and a sphere in which industry officials were seeking "maximalist" control le.g., through strict interpretation and enforcement of copyright) to counter the ease and speed by which digitized information can be copied and circulated. In a recent study, Cooper and Harrison (2001) profiled subcultures engaged in audio piracy through the exchange of music files on computer networks. Finally. Jones (2000) outlined several potential topics of study, such as the tension between "dis-" and "re-intermediation" created as industry players eliminate, transform, and re-allocate business functions.

The Napster controversy was foreshadowed by two intersections of computers and popular music in the 1980's. The first was authorized: Record companies formed experimental, inter-organizational networks with their wholesalers and retailers to facilitate marketing, distribution - and even point of sale production- of CDs (Nouwens \& Bouman, 1996). The second was more controversial: The use of computers (e.g., by club DJs) to "sample" and blend recorded music with other texts to create new forms. These two systems differed dramatically in their orientations to dominant commodity forms. While the first system sought to preserve the $C D$, the second viewed it as a malleable resource for improvisation and performance. Napster would ultimately blend the potential for exchange offered by the first system with the subversive impulse of the second.

In the 1990s, a critical instability emerged. The development of "codec" software (e.g., MP3) allowed personal computer (PC) users to "rip" recorded music from CDs, and convert it to digitized files that could be stored on hard-drives and exchanged over the Internet. During 1999, two young entrepreneurs developed the Napster software system, allowing free, direct, "peer-to-peer" (P2P) exchange of these files. Between September 1999 and July 2001, this service attracted approximately 70 million users. Seventy percent of their exchanges involved copyrighted material. These exchanges-peaking at 3 billion files per month (King, 2001f) - accounted for 
$15 \%$ of all Internet activity during this period (Hudson, 2001). This activity alarmed and infuriated the major record companies, who quickly filed a lawsuit through the Recording Industry Association of America (RIAA), claiming that Napster facilitated copyright infringement. In February 2001, a U.S. appeals court ruling upheld a previous, lower court injunction. This ruling led to a gradual shutdown of the service by July 2001.

These events created a complex aftermath. Following the court ruling, Napster users engaged in a final spasm of exchange (of 2.8 billion files; "Napster Eclipsed," 2001), and attempted to subvert imposed filters. Most migrated to alternate "free" sites (such as MusicCity.com), networks (such as FastTrack and Gnutella), and programs (e.g., Morpheus and Grokster), where they were joined by record numbers of other users. By the end of September 2001, activity on the four largest of these sites surpassed that of Napster at its peak (King, 2001b). These sites differed from Napster in three important ways. First, they were technologically de-centralized (e.g., by employing users' own computers as search engines), shifting both agency and legal accountability to their users. Second, they were used to exchange a variety of copyrighted materials, such as video ripped from DVDs. Finally, they were profitdriven, employing media such as banner advertisements to "capture eyeballs."

The major record labels such as AOL Time Warner subsequently banded together and partnered with Internet technology companies such as RealNetworks to develop fee-based, "rights-protection systems" (RPS) allowing for-profit, on-line distribution of their catalogs by either proprietary or licensed entities. MusicNet and Pressplay were two of the first "second-generation" services to emerge in the U.S. RPS vary in their regulation of exchange. Some systems employ digital copyright protection technology (DCPT) that prevents purchased CD's from being ripped or even played on PC's. Others "rent" music that can be temporarily downloaded, stored, and played on a PC. Some prevent the transfer of downloaded music to portable devices (Harris, 2001; Wong, 2001). Record companies also initiated litigation against alternative free sites (King, 2001c). Ironically, the development of RPS attracted criticism from antitrust regulators and music artists. The former expressed concern that record companies will limit how they license music online so as to control markets and ensure huge profits (Richtel, 2001b). The latter protested a lack of adequate consultation and projected compensation (Phillips \& Healey, 2001). Adding to the labels' woes, their current core market of adolescent consumers has been socialized in a culture of piracy (Schwartz, 2001). Those consumers are casting a jaundiced eye on the constraints imposed by RPS (King, 2001d), and on the currently unsatisfactory quality of the licensed sites (King, 2001e). All this has occurred for the major labels during a traumatic period of soaring expenses and declining profits (Leeds, 2001).

For their part, Napster officials made a series of moves to mollify the record labels, and to mainstream their beleaguered company. They partnered with the parent company of a major record label (Bertelsmann AG) to develop a fee-based service, and with three other labels in the MusicNet system. They established an escrow 
account to be used as an advance on royalties owed to copyright holders, and agreed to pay multimillion-dollar damages to music publishers for past copyright iniringement (King, 2001b). In a complex dance, Napster officials balanced this affiliation with encouragement of federal legislation to ensure favorable licensing agreements. These efforts were unsuccessful, however. Prevented by record labels from commencing official operations and deserted by investors, the company passed first into bankruptcy, and then liquidation, in September 2002.

Meanwhile, unofficial groups of software developers developed and circulated anti-encryption programs to defeat DCPT. These efforts were in turn mel with vigorous prosecution irom copyright holders invoking statutes of the 1998 Digital Millennium Copyright Protection Act.

In the sections below, we explore the significance of these developments using the lens of the cultural circuit. We apply the five key moments of that circuitRepresentation, Identity, Production, Consumption, and Regulation-to the case of Napster, comparing and contrasting our findings with those of du Gay, et al. (1997), in their study of the Sony Walkman. We conclude by considering the implications of this analysis for the viability of this model in analyzing the phenomena of cyberculture.

\section{Representation: Articulating the Meaning of Napster}

According to du Gay, et al. (1997), representation is "the practice of constructing meaning through the use of signs and language" (p. 24). Meaning is not "fixed" either by objects themselves or by individual authors. Instead, meaning is socially constructed through symbolic systems such as language (Hall, 1997).

In applying this view to the Sony Walkman, du Gay et al. (1997) discuss four strategies through which new meaning is established. The first strategy posits that it is derived "from something we already know." In this view, the "stereo-headphone" and "cassette-player" are existing signs that are carried forward in understanding elements of the Walkman. A second strategy is to associate an object with various discourses. For example, the Walkman is frequently articulated with other discourses, such as those of "high-technology" and "youth." As a result, the Walkman early on acquired connotative connections to advanced technology, the information revolution, pop music, and youth fashion. A third strategy is through employing signs as a marker of distinction. "It is difference which signifies" (du Gay, et al, 1997. p. 17). The Walkman differs, for example, from other traditional forms of personal audio technology in its compactness and portability. A final strategy involves articulating meaning by connecting artifacts with major cultural themes. Here, the Walkman evokes larger conversations about controversial matters, such as the impact of "privatized consumption" on traditional community structures.

Applying these strategies to an analysis of Napster yields the following findings. First, we find that the literal meanings of Napster also derived from familiar sources. 
For instance, Napster was described as a program used for "swapping" music files (see e.g. Harmon, 2000; "AOL to Launch," 2001; Healey, 2001a). Media coverage employed this term to capture the free and direct exchange of files between users. In doing so, commentators invoked a residual image of public, face-to-face interaction (e.g., the "swap meet") to assimilate the phenomena of cyberculture.

Secondly, like many cultural artifacts, Napster's meaning was not restricted to literal denotations. Rather, Napster formed a polysemic sign. Several examples indicate that its connotations were constructed through association with other discourses. One involved the figure of its youthful co-founder, Shawn Fanning (see, e.g., "Inside Napster," 2000; Levy, 2000; "Shawn Fanning's Struggle," 2000). In profiles of Fanning, Napster was frequently associated with a hegemonic discourse (e.g., the Horatio Alger myth) concerning the relationship between individuals and capitalist structures in American society. These stories emphasized Fanning's rise from a dysfunctional family and working class background, his entrepreneurial spirit, his (initial) corporate success, and the associated rewards of wealth and celebrity. A second example involved depictions of college students, who formed the critical mass of Napster users (see, e.g., Bromwich, 2001; Gurley, 2000; "Inside Napster," 2000; Yardley, 2000). In these depictions, Napster was associated with ambivalent cultural discourses about youth. These discourses mixed anxiety and admiration, invoking connotations of aggression, informality, leisure, energy, and rebellion against established forms of authority. For example, Napster was described as "hard-core 60's: free love, free music" (Yardley, 2000, p. 2). Finally, Napster also gained meaning through association with the discourse of high technology (Cohen, 2000; Kover, 2000; Levy, 2000; Mann, 2000). As a system, Napster was frequently articulated with other technological forms and practices. For instance, one journalist summarized Napster's operation as follows: "One click of the mouse and your computer hooks up with the one [song] you choose, sucking up the bits that will allow you to play back the song on your computer, on a Walkman-like MP3 player or even on a CD that you might 'burn' yourself" (Levy, 2000, p.49). Such use of terms like "burning," and "ripping" invoked a post-modern aesthetic of high-technology that fetishizes currency, speed, mobility, sleekness, manipulation, and the rapid destruction and reconstruction of matter (Brummett, 1999).

Applying du Gay, et al's (1997) third strategy of representation, we find that Napster signified because it marked a basic difference in how music is distributed and consumed in capitalism. As described above, Napster differed fundamentally from traditional music systems (e.g., broadcast radio) and commodity forms (e.g., the CD). Napster's peer-to-peer exchange format violated the music industry's traditional model of centralized distribution.

Finally, the meaning of Napster was indeed connected with wider conversations, most notably about the Internet's transformation of "brick and mortar" institutions premised on material contexts, hierarchy, and centralized control. In this way, the Napster controversy formed a social drama-an opportunity for media producers 
and audiences to work out through representation their larger anxieties, ambitions, and hopes surrounding the rapid evolution of computing technology.

To this point, we have seen that the four strategies of meaning-construction outlined by du Gay, et al. (1997) may also be applied to representations of Napster. This picture is somewhat static, however. To create a more dynamic image, we turn to Slack's (1989) application of Hall's theory of articulation to representations of technology. According to Slack (1989, p. 331), technology involves "a non-necessary set of specific connections formed in the conjuncture of other social forces, practices, identities, and ideology." In this view, the articulation of technological meaning is subject to dominant power relationships, but is also constitutive of their reproduction and transformation: "Different articulations empower different possibilities and practices" (p. 331). With a variety of political and economic consequences at stake, the representation of technology forms a site of constant struggle for the articulation of preferred and oppositional meanings.

Du Gay et al. (1997) certainly incorporate a view of cultural struggle in their analysis of the Sony Walkman. In analyzing Napster, however, a more dynamic view of its representation is warranted by the complexity and intensity of this case. In our view, Napster is a symbolic site of struggle where different discourses alternately make contact, affiliate, and clash with each other. A most basic example involves the passionate conflict conducted in regulatory and journalistic venues between populist speakers associating Napster-usage with "freedom of speech," and music industry speakers demanding the enforcement of copyright protections.

One example of this struggle is a text that circulated on the University of Colorado-Boulder campus during the spring of 2000, a period in which administrators were considering blocking Napster use on the institution's computer systems. In opposition to this plan, a student group posted a flyer juxtaposing the appeals "Save Napster" and "Stop Censorship." These appeals were illustrated with a photograph of Adolph Hitler, which was apparently intended to evoke associations between administrative action and fascist restrictions of speech. An alternate (and more historically-informed) reading of this text might have associated Napster's facilitation of copyright infringement with the Nazi seizure of Jewish-owned property. While this irony was lost on the flyer's authors, it nonetheless illustrates the polysemy of Napster representations. This text indicates a form of cultural politics. College students form a critical market for the music industry. While their use of Napster may or may not constitute a progressive practice, it does constitute an alternative form of agency that deviates from industry-preferred norms of predictable and passive consumption. As such, it is political-and undoubtedly pleasurable- to reverse a vast inequality of power and wealth. This campus flyer expressed and advanced the students' evolving interests in relation to Internet technology and traditional media industries. It also clarified the intermediate role of university systems administrators "hailed" both by threats of litigation from copyright holders, and by student sentiments favoring free speech (or at least free carriage). 


\section{Moments of Identity: What, Where, and Who is Napster?}

The problem of who I really am is raised by the facts of what I appear to be; and though it is essential to the mythology of authenticity that this fact should be obscured by its prophets, what I appear to be is fundamentally how I appear to others and only derivatively how I appear to myself. (Appiah, 1992, p. 121)

Conceptualizing Napster as a site of cultural politics leads inevitably to questions of identity. According to du Gay et al. (1997), technologies are given identities based on images of race, class and gender that are mobilized in their representations. Identities are discursive categories produced at the intersection of certain attributes, capacities, and forms of conduct at specific historical moments. Advertisements, for example, activate idealized images of self for consumers who seek to acquire the cultural characteristics represented by a product's depiction (Du Gay et al., 1997; Hall, 1997).

Appiah's epigram reminds us that these activations are always strategic; identities are scripted and imposed by others as resources for a desired performance of self (e.g., as individualist consumer). In this section, we argue that unlike the relatively stable, contained, and producer-defined identity of the Walkman, Napster's identity is more fragile and ambivalent. We explore a paradoxical, revolutionary identity configured around Napster in the discourse of its users, the RIAA, Fanning, and Napster, Inc. In constructing this identity, Napster's stakeholders activated various connotations that placed the organization in a dilemma involving affiliations with its user-base and the record industry. We also argue that, while both cases demonstrate how the identities of cultural artifacts are conflated with those of their organizations (and those organizations' founders), this ontological collapse is greater in the Napster case. As a result, Napster's co-founder Shawn Fanning became a contested icon in the struggle between Napster users and the RIAA.

In their analysis of the Walkman, du Gay et al. (1997) discuss how Sony co-founder Akio Morita was linked to the Walkman, Sony, and Japan itself in various commercial and journalistic discourses. They contend that stories of the Walkman's success interpellated the biography of Morita's life and the corporate history of Sony, binding that organizational identity to his personality. They also show how specific "lapanese" attributes (e.g., the aesthetic of simplicity) were articulated with Sony's "culture of production" (e.g., its encouragement of creativity) and the Walkman's features (e.g., miniaturization) to produce its identity as an artifact. However, much of this discussion is based on homogenous "official" discourse by, and about, Sony. There is little discussion of opposing stakeholder discourses, and the identity of Walkman consumers appears to be an "effect" of Sony's successful manipulation of image politics.

In contrast, the Napster controversy was characterized by multiple and competing discourses. According to Mann (2000), 40\% of P2P software users are 30 years old or over, a fact not commonly emphasized in depictions of Napster. Actual Napster 
users covered a full demographic spectrum from executives and lawyers to college students and teenagers (Selvin, 2001). Despite this diversity, many Napster users appeared to identify with Shawn Fanning, co-creator of Napsier and a stellar example of the 'Geek ascension'-the coming generation of techno-savvy youth whose skills are both required and resented by an older managerial class threatened with obsolescence (Katz, 2000). Described by Levy (2000, p. 49), for example, as a "slouchy, bullet headed, 19 year old college dropout," Shawn Fanning invited identification from youthful (and youth-oriented) consumers along various axes of affinity (Schevitz, 2001; Szudzick, 2001; Tench, 2001).

In 1999, as an obscure freshman at Northeastern University, Fanning designed the Napster program, using his childhood nickname to mark it as his creation. With his uncle's help. Fanning established Napster, Inc. as an Internet start-up in May 1999. receiving money from venture capitalists who, along with industry insiders and legal experts, formed the company's initial board of directors. Napster, Inc. subsequently employed several interim CEOs to direct company operations, but it was Fanning who initially formed the public face of Napster, both in journalistic coverage and user discourse. Napster's technology and corporation were conflated with images of Fanning as a music fan and audio pirate. As a participant in this process, Fanning simultaneously endeared himself to Napster users and evoked the ire of the RIAA.

Fanning's youth and technological genius, combined with his desire to share copyrighted music, inspired Napster users to view both him and his technology as revolutionary-an identity with serious consequences for both the music industry and conventional assumptions about consumers. As James Post (cited in Proctor, 2001, p.2B) observed, "Young Americans sympathize with an anti-exploitation principle. They have seen Napster as a protest against the rising prices for albums and concert tickets." Another user reported "I just think its neat he's messed things up like that ... I think he's cool" ("Copycats," 2001). For many users, it seemed that Napster's technology and Fanning's entrepreneurialism had wrought a brave new world of cyber-music (see, for example, Evangelista, 2001a; Ough, 2001). This world was profoundly anti-corporate: music was free, and Fanning/Napster enabled users to assume greater control over their music consumption. In viewing Fanning/Napster as revolutionary, they understood this identity to involve fundamental social and political change oriented to justice and equality (Franks, 1997; Tench, 20011. By identifying with Fanning, Napster users acted as members of a populist-libertarian Net-izen subculture. In this logic, Fanning/Napster initially appeared as a Robin Hood-like figure, taking music from an evil elite and giving it to the noble oppressed.

Inevitably, this groundswell invoked the wrath of the RIAA. In defending their interests, the RIAA re-coded revolutionary as renegade. In this counter-attack, negative images of radical change as an inherent threat to private property and social propriety were mobilized. Napster, Inc. and Fanning himself (by dint of personalization) were depicted by the president of the National Academy of Recording Arts and Sciences, Ron Green, as a "music industry bad boy," and "a haven for mass 
music piracy." Green further argued that "there is no difference between Napster and car thieves" (Evangelista, 2001b; Kornblum, 2001; "Napster Lays Claim", 2001).

In response to this withering criticism, and in anticipation of looming regulation, Napster, Inc. attempted to distance itself from its initial identity. Immediately following the February, 2001 court ruling, for example, the company argued that it could serve a legitimate role in the music industry as an independent distribution channel for artists. In this way, Napster, Inc sought to re-fashion itself as a procorporate revolutionary, joining a long line of companies that have appropriated counter-cultural images of social change to legitimate particular innovations in consumer capitalism (Franks, 1997). However, this connotation profoundly conflicted with the anti-corporate identity that had mobilized Napster users (many of whom felt betrayed), and abandoned the service. That Fanning himself did not realize the fragility of this identity is suggested in this quote from a recent interview: "Charging users for music has been difficult to get my head around ... I didn't expect it to become a business ..." (BBC News, 2001).

\section{Production: The Moment of Distribution?}

For du Gay et al. (1997), production is both material and cultural: it involves the basic creation of goods and services, as well as of cultural meanings. This integration of perspectives is reflected in their focus on "the culture of production" that surrounds the design, manufacture, and distribution of a particular cultural object: "the ways in which practices of production are inscribed with particular cultural meanings" (du Gay et al., 1997, p. 4). This culture, the authors note, "is an integral part of the company way of life that informs intra-organizational decisions and activities... [and] the perceptions of outside observers" (p. 43). In analyzing the Walkman's culture of production, the authors focus largely on media representations (e.g., in business news and advertising) surrounding the product, Sony, its corporate culture, and its CEOs. These representations are presumed to reveal the wider set of cultural relationships within which the Walkman is enmeshed. Additionally, du Gay et al. (1997) assert that consumption is the most critical element in articulating production: production furnishes material for consumption, but consumption fulfills the intentions and efforts of producers to create products that are useful and effective. Nonetheless, they caution that there is no "easy fit" between the two elements.

This approach yields insight into the Walkman's production. However, given several fundamental differences between Napster and the Walkman, we offer here a rather different emphasis. We begin by noting the significance of Napster's artifactual status as software, in comparison to the Walkman's hardware. Second, unlike the Walkman, which derived from Sony's existing corporate culture, Napster's invention largely preceded the construction of a supporting corporate entity. This means that while Napster may be inscribed with certain elements characterizing Internet start-up cultures (e.g., speed, innovation, disdain for tradition and authority, and 
reliance on venture-capital), it may also partly reverse the traditional flow of inscription by serving as a totem around which Napster, Inc. organizes itself. Third, while du Gay, et al. were able to trace Sony's arc across multiple decades, Napster was a "progeria[tric)" startup ("Disposable Corporation," 2001) that evolved quite quickly, leaving (as yet) no published analysis of the company's culture. Finally, in contrast to the Walkman, Napster emerged within a new age of digital production, distribution, and consumption. Positioned on the advancing wave of a P2P and codec storm, Napster disturbed an entire set of what du Gay et al. term productive "dependencies" and "interrelationships." Because of these contingencies, we argue that Napster's moment of production is most significant in facilitating a new mode of distribution. This development threatens powerful commercial interests configured around a tradition of production.

As discussed above, popular narratives typically situated Shawn Fanning at the core of Napster's production. This association of Napster with innovative, individual genius mirrored depictions of Akio Morita's role in the production of the Walkman. Indeed, in analyzing that history, du Gay et al. (1997) argue that cultures of production are deeply influenced by the visions of their founders (Schein, 1992). Traditionally, "founders" have been defined as entrepreneurs offering compelling visions of how the "right group of people" can create a superior product or service in the marketplace. This model has been substantially altered in the 1990s, however, by the "Internet start-up" phenomenon. These enterprises have been built around the creative powers of young, smart, and proudly informal knowledge workers. Until recently, their eagerness to challenge conventional understandings of business, market, and law was fueled by venture capital. Napster, Inc. exemplified this unique culture of production.

As the first company to exploit the fundamental P2P architecture of the Internet on a truly massive scale, Napster transformed traditional systems of music distribution. This transformation was inspired largely, though not exclusively, by the proliferation of information technology. "Napster," writes Lessig (2001, p. 135), "is the horse and buggy in this [P2P] transportation system. It is only the beginning." According to Dyer-Witherford (1999), the development of new modes of distribution reflects the relentless expansion of capitalism forecast by Marx. It was Marx, Dyer-Witherford reminds us, who noted that, "historically, capital tends to integrate the moments of production and consumption by expanding the circle of consumption to match the growing volume of goods it produced, and decreasing the turnover time by accelerating the speed with which goods passed from production to consumption" (p. 116). Similarly, Lessig (2001, p. 126) notes that "New products beget new markets and new modes of distribution (including the removal of barriers to distribution) induce the creation of new markets for existing products as well." In this way, even as it formed a threat to established modes of capitalism. Napster simultaneously represented the potential of technological innovation to facilitate capital's insatiable quest for ever-faster and -wider reproduction. 
Napster's impact on the recording industry was keenly felt by a wide range of "middlemen" such as agents, talent scouts, and managers who directly interact with artists, and the various professionals who perform marketing, public relations, promotion, sales, finance, legal, manufacturing, and distribution functions (Negus 1992, p. 38). Indeed P2P software such as Napster could be interpreted as the ultimate facilitator of "disintermediation": it potentially leads to the elimination of certain players within the traditional mode of production. Musicians, for example, can utilize Napster-like services to circumvent industry intermediaries, distributing their independently produced music directly to consumers. Potentially, this practice also eliminates major distributors and retailers (e.g., Tower Records) of popular music. At one point, in fact, Napster deliberately appealed directly to musicians to "control" their "destiny" and to "empower" themselves by putting Napster "to work" for them. However, predictions of the industry's death proved premature, and denied what Negus (1992) characterizes as the complex, resilient, and "web"-like nature of music production. Although successful self-promotion is certainly possible, without the promotional power of an established record company behind them, artists are almost certainly faced with difficulty in being heard against their competition.

The record industry clearly recognizes the potential of cyberspatial production and is attempting to alter its "business model(s)" accordingly. As discussed in the Introduction, the major labels are engaged in several ventures to develop RPS. Meanwhile, Napster attempted to refashion itself as commercial entity. But in so doing not only was it forced to shut down, it also lost most of its users.

The Internet's fundamental "ambivalence" thus distinguishes Napster's moment of production from the Walkman's. Simply put, Napster threatened an entire culture of production. In contrast, the Walkman conformed to and advanced the industrial mode of production. Napster demonstrated that, in cyber-culture, distribution is arguably the critical factor in articulations of production. "The Internet," notes Lessig (2001), "opens up a range of technologies for production and distribution that threaten the existing concentrations of media power" (p. 200). Ultimately, a stronger emphasis on distribution seems necessary for examining phenomena such as Napster.

\section{Consuming Napster}

In the case of Napster, consumption proved to be a powerful, meaning-making process to which other elements in the circuit of culture responded. Napster has caused, however, a profound shift in some of the traditional patterns within that circuit.

According to du Gay et al. (1997), an object's meaning is not determined solely during production but is instead subject to the impact of consumption patterns. Despite producers' efforts to elicit certain uses through advertising, design, and marketing, profits always depend on the ability to interpret changes in meaning that 
products undergo during consumption. In the case of the Walkman, Sony monitored how consumers used the device before and after it was released, incorporating that information back into the design, manufacture, and marketing of the product. For instance, when Sony dealers reported that consumers were using the product for outdoor activities, Walkman users began to be represented in ads as active and athletic. In response to consumer desire for an affordable, lightweight tape player, Sony decreased the number of parts and produced all components in its own factories. This move resulted in lower prices, lighter weight, smaller size, and greater portability for the device.

One of the main differences between the Walkman and Napster in the realm of consumption involved users' relationship with producers. While the Walkman was a commercial commodity purchased in traditional fashion, Napster subverted that power structure. Users did not "buy" anything, since the software was free. In this way, Napster, Inc. created an ambivalent and volatile relationship with its users. As discussed above, the company was caught in a paradox in which it could not officially acknowledge the anti-corporate "revolutionary" rhetoric adopted by its users without further intensifying its outlaw status among the music industry. As a result, it did not defend the actions of its users, and instead virtually disowned them when faced with lawsuits (and subsequently suffered their scorn). On the other hand, Napster at least initially recruited and relied on the agency of its consumers in the political struggle against regulation of the service, a dynamic that also was absent from the Walkman situation. Napster briefly attempted to assume a more traditional producer role, struggling to find a way to profit from its "revolutionary" technology, to turn its users into customers, to revert to a traditional licensed, and fee-based exchange system. (King, 2001a).

In the case of Napster, we also argue that the elements of production and consumption are more intertwined than in the case of the Walkman. Adopting a conventional definition of consumers (i.e., those who utilize commercial goods produced by others) to analyze the music industry, we find a number of internal and external "consumers": the record industry itself (which pays artists for songs and copyrights), Napster (which relied on the artists, the record industry, and CD purchasers to provide the music transmitted through its software and central server), and Napster users (who bought music from the recording industry and artists, or who downloaded MP3 files). All of these intertwined entities, including the Napster users who "ripped" the material from CDs also acted as producers, since they provided music to others.

Despite this condition, for the purposes of this analysis, we take Napster users to be the primary consumers. The act of consumption changed, however, because Napster empowered its users to obtain free songs while simultaneously making that music available to others. In the case of Napster, no longer were consumers abiding by the conventional rules of exchange (i.e., purchasing their music from retail outlets). Alternately, they subverted a variety of industry requirements, for example that they purchase recorded music in a particular commodity form (the $C D$ ) that 
inhibits previewing of contents, bundles marginal and superfluous music tracks, and obligates excess consumption. Napster consumers were thereby "liberating" the CD for the purpose of more customized pleasure and meaning (e.g., in burning personal mixes). This new consumption pattern prompted producers and regulators to construct new modes of discipline (discussed below).

The initial popularity of Napster, for example, prompted members of the heavy metal rock group Metallica to file suit against Napster in December, 1999, demanding that more than 300,000 filenames used to download its songs be expelled from the system. Ironically, these artists depicted their own fans as a group of thieves, contributing to the technology's "outlaw" image (Mann, 2000). Another example of how responses by producers to consumption patterns affected the meaning of technology occurred in March, 2001, when the U.S. 9th Circuit Court of Appeals ordered Napster, Inc. to cut off users' free access to copyrighted material. In a classic example of the dialectical struggle between strategies and tactics over the "margin of maneuver" (Feenberg, 1991), users immediately began to subvert the literalist codes of official filters by manipulating alphanumeric characters in their entries requested for song titles and artist names (Manjoo, 2001). The recording industry responded by asking the courts to compel Napster's use of stricter methods such as filtering out not just names but the files themselves, and using digital fingerprint technology (Richtel, 2001a). As discussed, the court's action accelerated Napster's shutdown, and an exodus of users to other free services ("Napster Eclipsed," 2001). Recording companies responded to this new form of consumption by selling individual songs online, or by selling subscriptions to music services. None of these systems, however, allow permanent storage of downloaded songs (i.e. without continued payment of fees), apparently for fear of competing with existing distribution outlets. Industry analysts question whether these "legitimate" services can attract a large number of subscribers, since most existing users are already accustomed to obtaining their music for free (Richtel, 2001c). Whether the recording companies have taken legal action, decided to appropriate the technology themselves, or both, Napster and its users have had a profound impact on the way music will be produced and consumed in the future.

A parallel restructuring of this relationship has been discussed by Jenkins (1992) in his famous study of fan subcultures whose members refashion media texts to satisfy their longing for alternative narratives corresponding to their positioned desire. As do the authors of the Walkman study, Jenkins rejects the notion that consumers are passive beings who absorb dominant meanings encoded in textual production. Alternately, he invokes de Certeau's image of the "poacher" to describe how fans empower themselves by appropriating popular texts for their own use. Jenkins argues that consumption often involves active reclamation of textual material. Quoting de Certeau, he characterizes audiences as "travellers; they move across lands belonging to someone else, like nomads poaching their way across fields they did not write, despoiling the wealth of Egypt to enjoy it themselves" (1992, p. 24). This image of cunning and tactical consumers reassuming control of copyrighted material in 
defiance of tyrannical regimes of production surfaced throughout discourse surrounding Napster. According to Jenkins, fans "may resist legal constraints on their pleasure and challenge attempts to regulate the production and circulation of popular meanings" (1992, p. 32).

Significantly, Jenkins' study primarily involved fans revising and circulating texts without profit in limited circles - not the widespread trading of copyrighted material otherwise intended for purchase. But there are similarities between the two cases. By circumventing the CD format, Napster users—like the Star Trek fans-violated the integrity of the dominant commodity form, and subverted the roles they were expected to play in reproducing corporate profits and cultural hegemony. Recent advances in online music access echo Jenkins' work even more closely: Indeed, now there are Internet-based services that allow users to create, karaoke-like, their own versions of popular songs and videos, mixing and blending their own voices, instrumentals and rhythms with original recordings (Healey, 2001a).

\section{Regulating Napster}

In conceptualizing the moment of Regulation, du Gay et al. (1997) discuss both formallegal and informal/ocal attempts to control cultural activity. The Walkman is a particularly interesting technology, they conclude, because it partly reverses an ongoing retreat by cultural members from active, civic involvement to privatized consumption "by taking private listening into the public domain" (p. 114). In response to this disruption, initial regulatory practices attempted to contain the Walkman within established classifications of the public and private spheres. In this way, while the Walkman's popularity has "firmly established it as a part of the modern soundspace," its assimilation has been tense and precarious (p. 120). Initial public use of the Walkman, for example, elicited public complaints about sound leakage that Sony quickly assimilated by manufacturing quieter earphones for the device. Du Gay et al.'s primary concern is with informal cultural regulation. Their analysis demonstrates that, while the Walkman has also inspired considerable public commentary, it has not, like Napster, been subject to intensive legal regulation. Therefore, we emphasize here the web of formal/egal regulation that surrounds Napster, while also expanding the concept of "informal" regulation to show how producers have attempted to re-articulate production and consumption through technological innovation.

Despite a nod to some progressive interests, formal regulation of Napster was dominated by the logic of capital. One example involved the recording industry's decision in 1999 to sue Napster itself, and not its individual users. The latter course would have generated both a logistical and public-relations nightmare for the recording industry. It would have further alienated its consumers, jeopardized its revenue streams, and left a rogue entity only indirectly punished. Alternately, Napster was subject to a dominant logic in which "ideas" (and their commodified 
expressions) were considered intellectual property. Because P2P software de- and re-materializes recorded music and distributes it in new ways, it has proven tremendously difficult to regulate. Despite this challenge, producers have historically proven adept at protecting copyright (Bettig, 1992). When a potentially subversive technology threatens a particular configuration of copyright, that technology is systematically "enclosed" via formal regulatory and industrial practices (Bettig, 1997). Writing before the Napster controversy, Bettig observed that this conflict evolves in a predictable sequence. First, a new technology/medium is introduced, and the owners of copyright temporarily lose control over the circulation of commodities. Second, elements of an industrial-productive "core" respond by appropriating "peripheral" firms and controlling their innovative technologies. Finally, this core mobilizes legal institutions to adapt copyright laws to ensure continued protection of their economic interests (pp. 140-143).

Napster's rapid evolution from a potentially counter-hegemonic technology into an aspiring, investor-driven profit-center confirms Bettig's analysis. After exhausting its willingness to challenge the recording industry (i.e., in further alienating the major labels, Napster risked being refused the opportunity to purchase licenses to distribute their catalogs), Napster attempted to refashion itself as a legal, fee-based service. In so doing, it solicited investment from both venture capitalists as well as music industry giants, and initiated the repayment of damages for previous infringement.

Napster thus demonstrated the potential for ambivalent technology to be activated in ways that threaten existing institutions, which in turn activate the "enclosing" structures of copyright regulation. According to Lessig (1999), however, technology may also evolve in a path more immediately compatible with capitalist interests. As discussed above, Lessig has noted the profound threat that the Internet's decentralized architecture poses to traditional copyright. He also notes, however, a proliferation of RPS and DCP technologies (e.g., "digital watermarking") that may adequately protect that tradition. Ideally, the agents of formal regulation grasp and balance these competing costs and benefits. Lessig (1999) argues, for example, that the Supreme Court has historically exercised extensive and careful review before concluding that a technology should be banned. Lessig concludes that this deliberate approach was warranted in the case of Napster. While the software firm clearly facilitated the illegal sharing of copyrighted material, it also embodied many potentially useful and legal functions. These included the exchange of non-copyrighted music and other content, and of (where authorized) copyrighted material. Other scholars (Kover, 2000; Mann, 2000) have agreed that Napster's infrastructure facilitated a greater diversity of cultural content, and thus served democratic interests historically encoded in copyright regulation.

The recording industry, however, held a considerably different view. It conceived of P2P primarily as a threat (and reluctantly, as an opportunity), and mobilized formal regulation to shape cyberspace as much as possible according to its commercial imperatives. Indeed, Lessig has most recently (2001) argued that entrenched interests, who have successfully mobilized legal regulation to protect their interests, 
threaten Internet innovation. In fact, the recording industry has not limited itself to legal challenges. As mentioned above, it is also seeking to re-articulate production and consumption through technological innovation. A consortium of music labels, retailers. consumer-electronic firms, information-technology companies, and trade associations, for example, has assembled to create the Secure Digital Music Initiative (SDMI) (Mann, 2000). Its goal is to create DCPT that will permit the industry to release music on the Internet without fear of uncontrollable circulation. Users will be able to exchange files, but SDMI technologies will control the circumstances under which those files can actually be stored and played. MusicNet serves as an example. Powered by SDMI participant RealNetworks, MusicNet restricts the number of songs subscribers may download and forces them to use proprietary media players to play downloaded music. Because these developments constitute the mobilization of production to discipline consumption in conjunction with formal regulation, we believe that they should also be considered as a type of "informal," or at least parallel, regulation.

This mobilization has in turn been countered by hackers laboring to create software (e.g., Freenet) that will defeat DCPT initiatives. Alternate free systems such as Gnutella, MusicCity, Morpheus, and KaZaA form an additional challenge for the recording industry by way of their decentralized nature and informally maintained architecture. A successful RIAA lawsuit brought against owners of the Aimster (a.k.a., Madster) system (which permitted users to exchange digitized music files through AOL's Instant Messenger channels) indicates that the recording industry employs a harsh standard in interpreting ambiguous, multi-functional technologies, and seeks to chill their development. The RIAA has also filed suit against MusicCity and KaZaA. In addition, the RIAA has pressured Internet Service Providers (ISPs) to cut off subscribers using P2P software to exchange copyrighted music files.

In the mundane practices of cyber-culture, official attempts to regulate Napster were variously accommodated, negotiated, and opposed by consumers. Such practices involve both "informal" regulation, and more explicit insurgency. An example of the former occurred in our writing of this paper, when one co-author (Jeff Dodge) proudly announced to his wife that he had, for the purposes of "research," downloaded his first music file from Napster. Since Jeff's spouse is a professional musician, she responded with a spirited defense of artistic interests in this controversy. Jeff has not downloaded since. An example of tactical resistance to regulation (the subversion by Napster users of court-imposed filters) has been discussed above. This particular practice in turn provoked a re-articulation of regulation, production, and consumption: Under continued pressure from the RIAA to enforce the court ruling, Napster began requiring its users to download an updated version of its software that allegedly prevented the use of scrambling and pseudonyms. Napster eventually moved to halt downloads of its software altogether. These acts of compliance also resonate across the moment of production: In addition to disciplining users, they might otherwise have inspired investors.

What is consistent across these examples is the expressed desire by all interests to 
exploit technological advantage, and create preferred relationships. These visions differed widely, however, and the result was ongoing struggle. In this way, there are significant differences between the Walkman and Napster cases. As the invention of entrepreneurs, Napster was developed outside the bounds of formal industrial production. The Walkman, in contrast, emerged from within the confines of Sony's established infrastructure. For this reason, and because it did not facilitate unauthorized copying of protected materials, the Walkman did not activate formal regulation. Because it radically challenged traditional modes of production, however, Napster provoked and suffered that institutional wrath.

\section{Conclusion}

We have used the circuit of culture model here to compare du Gay, et al.'s (1997) study of the Sony Walkman with the case of Napster. We have tried to assess how Napster, as an exemplary cyber-cultural phenomenon, accommodates the use of this model.

Our findings may be summarized as follows. In the moment of Representation, Napster displays strategies of meaning construction similar to those described by Hall (1997). However, it indicates that the increased scope and rate of change produced by new media may intensify the role of representation in the struggle for meaning. Adopting various stances of anxiety, bemusement, indignation, and envy, various discourses in cyber-culture rush ahead of (e.g., as speculation), alongside (as analysis), and behind (as history) technological innovation. They provide stories that alternately facilitate and disrupt its assimilation (Fisher \& Wright, 2001). Concerning Identity, Napster displays both similarities and differences. In both cases, technologies and their cultures of production were personified through the icon of their developers. Napster stakeholders. however, mobilized Shawn Fanning's identity more explicitly as a strategy for empowering and constraining user agency. Additionally, the Napster case does not yield "advertising" discourses that provide data comparable to the Walkman study (Napster never needed to formally advertise). In the moment of Production, we see the greatest difference. The authors of the Walkman study do not problematize distribution, but this moment-within-a-moment is central to the Napster case. Additionally, the model needs here to accommodate a reversal displayed in Internet start-ups of the traditional Company-begets-Innovation sequence, and also to match the extraordinary speed with which those cultures evolve. In Consumption, we note a key difference in Napster's profound collapse of distinctions between the practices of production and consumption (e.g., in users' ripping and exchange of purchased music). Additionally, Napster's dilemma of converting "users" into "customers" indicates the need for the model to accommodate finer distinctions in modes of consumption, and to monitor the ongoing "enclosure" of non-traditional consumption. In this way, Sony never had to cope 
with the problem of consumers using the Walkman without paying for it. Finally, in the moment of Regulation, we find a spectacular difference between the two cases in the degree of formal regulation, and a potential revision of informal regulation to include the mobilization by producers of technological innovation to rearticulate production and consumption in ways that complement formal regulation.

We do not argue, then, that the Napster case is necessarily the best example of a cyber-cultural circuit, or that this model is the only or best tool for analyzing cyber-cultural phenomena. We do argue, however, that applying this model to this case indicates that the evolution of new media should be matched by vigilance in testing research concepts and methods. This argument does not assume that every technological innovation will require corresponding changes in scholarship. Indeed, the model's flexibility has contributed to its utility and popularity. Instead, the Napster case indicates that media scholars should reflect carefully on these issues as they negotiate the competing demands for relevance and significance in their work.

\section{References}

AOL to launch new music initiatives (2001, July 23). Retrieved August 7, 2001 from the World Wide Web: http://www.nyt.com

Appiah, K. A. (1992). In my father's house. London: Methuen.

Barker, C. (2000). Cultural studies: Theory and practice. Thousand Oaks, CA: Sage

BBC News. (2001, June 26). Napster signs deal with Indie labels. Retrieved June 26, 2001 from the World Wide Web: http://news.bbc.co.uk/hi/english/business/newsid_1408000/ 1408683.stm.

Bell, D., \& Kennedy, B. M. (Eds.). (2000). The cybercultures reader. New York: Routledge.

Bettig, R.V. (1992). Critical perspectives on the history and philosophy of copyright. Critical Studies in Mass Communication, 9, 131-155.

Bettig, R.V. (1997) The enclosure of cyberspace. Critical Studies in Mass Communication, 14, 138-157.

Bolter, I. D., \& Grusin, R. (2000). Remediation: Understanding new media. Cambridge, MA: MIT Press.

Bromwich, D. (2001, February 24). The Napster specter. The Washington Post, p. A23.

Brummett, B. (1999). Rhetoric of machine aesthetics. Westport, CT: Praeger.

Caldwell, J. T. (Ed.) (2000). Electronic media and technoculture. New Brunswick, NJ: Rutgers University Press.

Chesebro, J. W., \& Bertelsen, D. A. (1996). Analyzing media: Communication technologies as symbolic and cognitive systems. New York: Guilford Press.

Clarke, J. (1991). New times and old enemies: Essays on cultural studies and America. London: HarperCollinsAcademic.

Cohen, W. (2000, March 6). Napster is rocking the music industry. US News and World Report, 128, 41.

Cooper, J., \& Harrison, D. (2001) The social organization of audio piracy on the Internet. Media, Culture and Society, 23, 71-89.

Copycats: Teens like the idea of file sharing on the Intemet but some say it's wrong. (2001. March 25). Pittsburgh Post-Gazette, p. W3.

Du Gay, P.(1997). Production of culture: Cultures of production. London: Sage. 
Du Gay, P., Hall, S., Janes, L., Mackay, H. \& Negus, K. (1997). Doing cultural studies: The story of the Sony Walkman. London: Sage.

Dyer-Witherford, N. (1999). Cyber-Marx: Cycles and circuits of struggle in high-technology capitalism. Umana: University of Illinois Press.

Evangelista, B. (2001a, March 4). Napster heirs vie for fans. San Francisco Chronicle, p. B1.

Evangelista, B. (2001b, March 7). Judge tightens noose on Napster. San Francisco Chronicle, p. A1.

Feenberg, A. (1991). Critical theory of technology. New York: Oxford University Press.

Ferguson, M., \& Golding, P.(Eds.). (1997). Cultural studies in question. London: Sage.

Fisher, D. R., \& Wright, L. M. (2001). On utopias and dystopias: Toward an understanding of the discourse surrounding the Intemet. Journal of Computer Mediated Communication, 6. Retrieved December 16, 2001 from the World Wide Web: http://www.ascusc.org/jcmc/vol6/ issue2/fisher.html

Franks, T. J. (1997). The conquest of cool: Business culture, counterculture and the rise of hip consumerism. Chicago: University of Chicago Press. 326.

Gurley, J. W. (2001, May 1). Want to stop Napster? Forget it-it's too late. Fortune, 141, p.

Hall, S. (1981). Encoding/decoding. In S. Hall, D. Hobson, A. Lowe \& P. Willis (Eds.), Culture, media, language. London: Hutchinson. Sage.

Hall, S. (1997). Representation: Cultural representations and signifying practices. London:

Harmon, A. (2000, August 6). Online David vs. corporate Goliaths. The New York Times, p.1.

Harris, R. (2001, August 26). Recording industry experimenting with hacker-proof CD's. The Salt Lake Tribune, pp. E-1, 6.

Hayward, P. (1995). Enterprise on the new frontier: Music, industry and the Internet. Convergence, 1, 29-44.

Healey, J. (2001a, July 23). Record labels prepare their online assault. Retrieved December 16, 2001 from the World Wide Web: http://www.latimes.com/business/ la-000060022ju123.story

Healey, J. (2001b, October 4). Mixed messages. Los Angeles Times. Retrieved Feb. 1, 2001 from the World Wide Web: http://www.latimes.com/technology/la-000079242oct04.story

Hudson, K. (2001, August 12). Lines lie silent as demand falls short. Denver Post, p. 1L, 4L. Inside Napster. (2000, August 14). Business Week, 3694, p. 112.

Jenkins, H. (1992). Textual poachers: Television fans and participatory culture. New York: Routledge.

Johnson, R. (1986/1987). What is cultural studies anyway? Social Text, 16, 38-80.

Jones, S. (2000). Music and the Internet. Popular Music, 19, 217-230.

Julier, G. (2000). The culture of design. London: Sage.

Katz, J. (2000). Geeks: How two boys rode the Internet out of Idaho. New York: Villard.

King, B. (2001a, September 7). Napster's new tune: Pay labels. Wired News. Retrieved January 27, 2002 from the World Wide Web: http:/www.wired.com/news/mp3/ $0,1285,46636,00 . h t m l$

King, B. (2001b, September 24). Napster settles, eyes relaunch. Retrieved December 16, 2001 from the World Wide Web: http://www.wired.com/news/mp3/0,1285,47075-2,00.html

King, B. (2001c, December 10). Napster still playing, in court. Retrieved December 16, 2001 from the World Wide Web: http:/www.wired.com/news/digiwood/0,1412,489822,00.html

King, B. (2001d, December 18). Music so nice, you may pay twice. Retrieved January 12, 2002 from the World Wide Web: http://www.wired.com/news/mp3/0,1285,49188,00.html

King, B. (2001e, December 20). Music a pol can subscribe to. Retrieved January 12, 2002 from the World Wide Web: http://www.wired.com/news/mp3/0,1285,49266,00.html

King, B. (2001f, December 22). MP3 downloads into Europe. Retrieved January 12, 20002 from the World Wide Web: http://www.wired.com/news/mp3/0,1285,49342,00.html 
Kornblum, I. (2001. March 8). Make a new plan, Stan: Napster facing more suits. USA Today, p. 3D.

Kover, A. (2000, June 26). The Hot Idea of the Year. Fortune, 132-136.

Leeds, J. (2001, December 26). Labels singing the blues over expensive failures. Retrieved January 12, 2002 from the World Wide Web: http://www.latimes.com/business/ la-0000102156dec26.story

Lessig, L. (1999). Code and other laws of cyberspace. New York: Basic Books.

Lessig, L. (2001). The future of ideas: The fate of the commons in a connected world. New York: Random House.

Levy, S. (2000, June 5). How a program that lets you get music free from the Web has ignited the first great battle of the Internet century. Newsweek, 47-53.

Lewis, J. (1994). Reflections on the encoding/decoding model: An interview with Stuart Hall. In J. Lewis, \& I. Cruz (Eds.), Viewing, reading, listening: Audiences and cultural reception. Boulder, CO: Westview Press.

Manjoo, F.(2001, March 15). Napster sharers sharing less. Wired News. Retrieved April 9 2001 from the World Wide Web: http://www.wired.com.news/culture/0,1284,42452,00.html.

Mann, C. C. (2000). The heavenly jukebox. The Atlantic Monthly, 286, pp. 39-59.

Morochove, R. (2001, June 7). Online music is here to stay. Toronto Star, p. H03.

Napster eclipsed by newcomers. (2001, September 6). Wired News. Retrieved January 27, 2002 from the World Wide Web: http:/www.wired.com/news/business/0,1367,46596,00.html Napster lays claim to legitimacy. (2001, June 14). Irish Times, p. 8.

Negus, K. (1992). Producing pop: Culture and conflict in the popular music industry. London: Edward Arnold.

Nouwens, J., \& Bouwman, H. (1996). Living apart together in electronic commerce: The use of information and communication technology to create network organizations. Journal of Computer Mediated Cummunication, I. Retrieved December 9. 1997 from the World Wide Web: http://www.ascusc.org/jcmc/vol1/issue3/nouwens.html

Ough, M. (2001, March 4). Napster gives me music I want to hear. The Ottawa Citizen, p. A15.

Phillips, P. \& Healev, I. (2001, December 10). Round 2 of online music battle begins. Retrieved December 16, 2001 from the World Wide Web: http://www.latimes.comtechnology/ la-000098124dec10.story

Proctor, D. (2001. March 5) Young users don't condemn Napster. Rocky Mountain News, p. $2 B$.

Richtel, M. (2001a, March 28). Recording group asks U.S. court for tighter controls on Napster. Retrieved April 9, 2001 from the World Wide Web: http://www.nytimes.com/2001/ 03/28/technology.html

Richtel, M. (200Ib, August 7). Plans to sell music on the Internet raise antitrusl concerns.

Retrieved December 16, 2001 from the World Wide Web: http://www.nyt.com

Richtel, M. (2001c, September 29). Free music service is expected to surpass Napster. New York Times. Retrieved January 27, 2002 from the World Wide Web: http://college3. nytimes.com/guests/articles/2001/1 1/29/885514.xml

Schein, E.H. (1992). Organizational culture and leadership. San Francisco: Jossey-Bass. Schevitz, T. (2001, March 7). No Napster? No problem. San Francisco Chronicle, p. A4. Schofield, J. (2001, May 10). Long live the Napster revolution. The Guardian, p. 57.

Schwartz, I. (2001, December 25). Trying to keep young Internet users from a life of piracy.

Retrieved January 12, 2002 from the World Wide Web: hitp:/www.nyt.com

Selvin, J. (2001, June 3). A Napster eulogy. San Francisco Chronicle, p. 61.

Shawn Fanning's struggle. (2000, May 1). Business Week, 3679, p.197.

Slack, J. D. (1989). Contextualizing technology. In B. Oeruin, L. Grossberg, B. O'Keefe \& E. Wartella (Eds.). Rethinking Communication: Volume 2-Paradigm Exemplars (pp.329-345). Newbury Park, CA: Sage.

Soar, M. (2000). Encoding advertisements: Ideology and meaning in advertising production. Mass Communication \& Sociely, 3, 415-437. 
Szudzik, C. (2001, March 27). A music revolution. The Buffalo News, p. N2.

Tench, M. (2001, March 11). Napster fans say they're taking the moral high ground. Toronto Star, p. BOD.

The disposable corporation. (2001, April) Wired Magazine, p. 183.

Wong, M. (2001, August 27). Electronics industry adding digital locks to audio components. The Salt Lake Tribune, pp. D-1, 3.

Yardley, J. (2000, May 8). The Napster generation. The Washington Post, p. C2. 